\title{
Control of fluid balance guided by body composition monitoring in patients on peritoneal dialysis (COMPASS): study protocol for a randomized controlled trial
}

\author{
Seon Ha Baek ${ }^{1 \dagger}$, Kook-Hwan Oh ${ }^{2 \dagger}$, Sejoong Kim, Dong Ki Kim², Kwon-Wook Joo², Yun Kyu Oh \\ Byoung Geun Han ${ }^{4}$, Jae Hyun Chang ${ }^{5}$, Wookyung Chung ${ }^{5}$, Yon Su Kim ${ }^{2}$ and Ki Young Na ${ }^{\text {* }}$
}

\begin{abstract}
Background: The clinical benefits of bioimpedance spectroscopy (BIS)-guided fluid management in patients on hemodialysis have been widely demonstrated. However, no previous reports have evaluated the effect of regular and serial BIS-guided fluid management on the residual renal function (RRF) in patients on peritoneal dialysis (PD). Therefore, we will evaluate the clinical efficacy of BIS-guided fluid management for preserving RRF and protecting cardiovascular events in patients on PD.
\end{abstract}

Methods/design: This is a multicenter, prospective, randomized controlled trial. A total of 138 participants on PD will be enrolled and randomly assigned to receive either BIS-guided fluid management or fluid management based only on the clinical information for 1 year. The primary outcome is the change in the glomerular filtration rate (GFR) between months 0 and 12 after starting treatment. The secondary outcomes will include GFR at month 12, time to the anuric state (urine volume $<100 \mathrm{ml} /$ day), and fatal and nonfatal cardiovascular events during treatment.

Discussion: This is the first clinical trial to investigate the effect of BIS-guided fluid management on RRF and for protecting against cardiovascular events in patients on PD.

Trial registration: Clinical Trials.gov number NCT01887262, June 24, 2013.

Keywords: Fluid balance, Bioimpedance spectroscopy, Peritoneal dialysis

\section{Background}

Overhydration $(\mathrm{OH})$ is common, and is associated with cardiac dysfunction and mortality in patients on peritoneal dialysis (PD) [1,2]. By contrast, volume depletion is associated with a more rapid loss of residual renal function (RRF) in patients on PD [3]. Therefore, euvolemia is one of the prime objectives in these patients.

In clinical practice, the volume status is indirectly assessed using various clinical data, including edema, weight gain, and hypertension [4]. Although there is a linear relationship between blood pressure (BP) and

\footnotetext{
* Correspondence: kyna@snubh.org

${ }^{\dagger}$ Equal contributors

'Department of Internal Medicine, Seoul National University Bundang Hospital, 82, Gumi-ro 173 Beon-gil, Bundang-gu, Seongnam 463-707,

Gyeonggi-do, South Korea

Full list of author information is available at the end of the article
}

tissue hydration, a substantial proportion of patients do not follow that pattern. A number of patients who are euvolemic or underhydrated have systolic hypertension. Volume reduction to control systolic hypertension may result in dehydration in these patients, which may decrease RRF or compromise coronary artery perfusion, and may result in acute myocardial infarction [5]. Conversely, patients with congestive heart failure may have a low or normal BP despite $\mathrm{OH}$. Therefore, BP cannot reflect changes in the hydration status [2].

Bioimpedance spectroscopy (BIS) has been used to measure the water compartment of the body [6]. In patients on dialysis, body composition, including extracellular water (ECW) and intracellular water (ICW), muscle mass, and fat mass, changes slowly over several months. Regular monitoring of body composition using BIS can facilitate

\section{Ciomed Central}

(c) 2014 Baek et al.; licensee BioMed Central Ltd. This is an Open Access article distributed under the terms of the Creative Commons Attribution License (http://creativecommons.org/licenses/by/4.0), which permits unrestricted use, distribution, and reproduction in any medium, provided the original work is properly credited. The Creative Commons Public Domain Dedication waiver (http://creativecommons.org/publicdomain/zero/1.0/) applies to the data made available in this article, unless otherwise stated. 
the optimal management of fluid balance in patients on dialysis.

The purpose of the present study is to evaluate the clinical usefulness of BIS-guided fluid management for preserving RRF and protecting against cardiovascular events in patients on PD.

\section{Methods/design}

Hypothesis

BIS-guided fluid management will preserve RRF in patients on PD better than fluid management guided by clinical information alone, such as BP, body weight (BWT), and physical examination results.

\section{Study design}

The study is a multicenter, prospective, parallel-group, open-label, randomized controlled trial. It is an investigator-initiated clinical trial. The study algorithm is depicted in Figure 1. After enrollment, clinical follow-up will be performed after $0,2,4,6,8,10$, and 12 months of treatment.

\section{Study participants and measurements}

All patients will be selected from the outpatient renal clinic of five tertiary hospitals in Korea (Seoul National University Bundang Hospital, Seoul National University Hospital, Seoul National University Boramae Medical Center, Gachon University Gil Hospital, and Wonju Severance Christian Hospital). Patients aged 20 to 75 years who are on PD and have a daily urine output of more than $500 \mathrm{ml}$ will be screened [7]. The following tasks will be conducted at the initial visit: 1) completion of questionnaire on medical and drug history, including the use of anti-hypertensive medication and diuretics; 2) physical examination of all body systems; 3) measurement of height and weight with an empty abdomen; and 4) BP and pulse rate measurement. Participants who meet all of the inclusion and exclusion criteria and who provide written informed consent will be eligible for this study.

\section{Inclusion and exclusion criteria}

Inclusion criteria were: age between 20 and 75 years; duration of PD (automated peritoneal dialysis (APD) or continuous ambulatory peritoneal dialysis (CAPD)) $>4$ weeks; daily urine output $>500 \mathrm{ml}$; and provision of written informed consent.

Exclusion criteria were: contraindication to bioimpedance measurement (amputation, presence of pacemaker, defibrillator, prosthesis, or metal implants); probable discontinuation of PD or receipt of kidney transplant within 1 year; hypoalbuminemia (serum albumin $<3.3$ $\mathrm{g} / \mathrm{dl}$ ); severe heart failure (New York Heart Association Functional Classification (NYHA FC) III or IV); combined dialysis modality (PD + intermittent hemodialysis (HD)); pregnancy, lactation; enrollment in other clinical trials within 1 month; uncontrolled hypertension ( $>160$ / $100 \mathrm{mmHg}$ with more than three anti-hypertensive medications); cardiovascular diseases (cerebral infarction, hemorrhagic infarction, acute myocardial infarction, or unstable angina) and acute infection (pneumonia, peritonitis) within 3 months prior to the trial.

Serum and urine creatinine $(\mathrm{Cr})$ will be measured by the isotope dilution mass spectrometry-traceable method using a TBA 200FR Analyzer (Toshiba, Tokyo, Japan). GFR will be calculated as the average $\mathrm{Cr}$ and urea clearance, which is measured by urine collection [8].

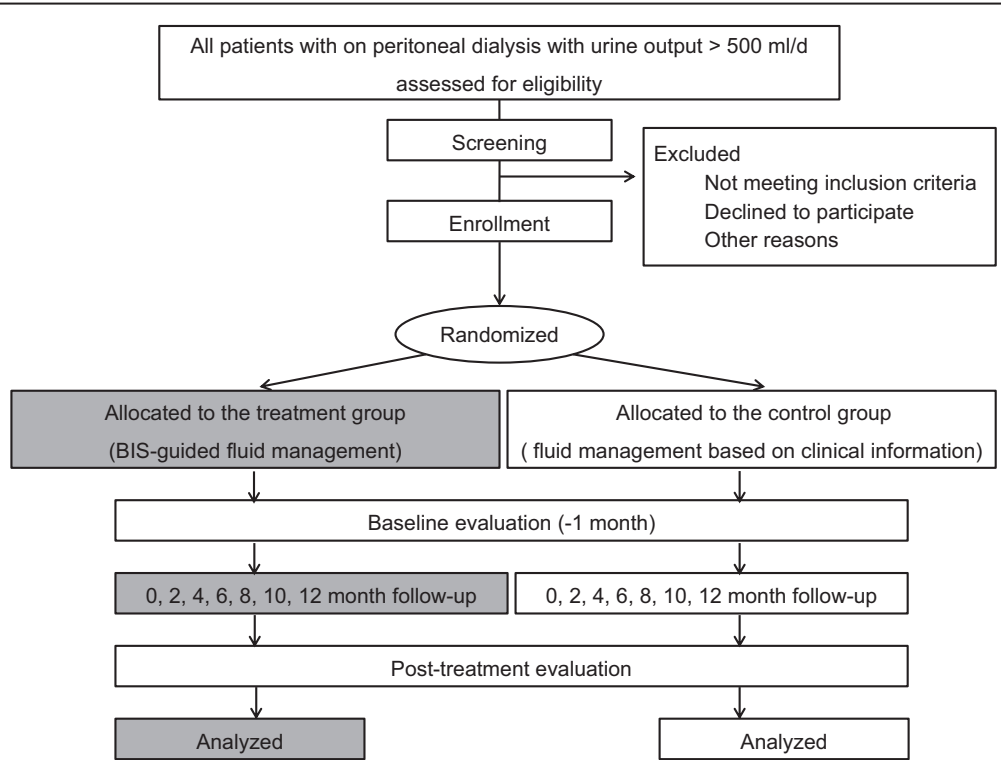

Figure 1 Study algorithm. BCM, body composition monitoring. 


\section{Randomization}

The randomization process will be conducted using a web-based computer program. A list of random numbers will be generated by a computerized random allocation system operated by the Medical Statistics Support Team in Seoul National University Hospital. Eligible participants will be randomly assigned 1:1 to either the control group (fluid management based on the clinical information alone) or treatment group (BIS-guided fluid management along with clinical information). Randomization will be stratified based on the institution and presence of diabetes mellitus, and will utilize a randomized block design.

\section{Outcome measures}

The primary outcome is the change in GFR between months 0 and 12 after starting treatment. The secondary outcomes will include GFR measured by urine collection, calculated by the mean of the $\mathrm{Cr}$ and urea clearance at month 12; time to the anuric state (urine volume $<100 \mathrm{ml} /$ day); and fatal and nonfatal cardiovascular events, including acute myocardial infarction, stroke, unstable angina, and cardiovascular revascularization. Parameters obtained by echocardiographic measurements, such as the left ventricular mass index, E/e' ratio, left ventricular end-diastolic pressure, left ventricular ejection fraction, left atrial volume index, and BP at month 12; parameters measured by BIS, such as the $\mathrm{OH}$ value, ECW, and ECW/ICW; hospitalization, cardiovascular and allcause mortality, and transfer to HD over the course of 1 year; pulse wave velocity (PWV), type and number of PD fluid and diuretics at month 12, and laboratory findings including high-sensitivity $\mathrm{C}$-reactive protein (hsCRP), N-terminal prohormone of brain natriuretic peptide, and cardiac troponin $\mathrm{T}$, will also be evaluated as tertiary outcomes.

\section{Assessment of the fluid status}

For participants in the control group, clinical information obtained by physician physical examination is the standard of judgment. Clinical information is composed of four items, including measured BWT within $2 \mathrm{~kg}$ of the dry weight, BP less than 140/90 $\mathrm{mmHg}$, absence of symptoms and signs for hypervolemia (dyspnea, edema, and crackle) or hypovolemia (dizziness and orthostatic hypotension).

For participants in the treatment group, the $\mathrm{OH}$ value measured by the Body Composition Monitor (BCM) (Fresenius, Medical Care Korea, Seoul, Korea), using an alternating current at 50 different frequencies $(5-1000 \mathrm{kHz})$ combined with clinical information, represents the standard of judgment. The $\mathrm{OH}$ value is calculated using the BCM based on a physiologic tissue model that is composed of the individual's normal ECW, normohydrated lean and adipose tissue. The $\mathrm{OH}$ value can be calculated from the difference between the normal expected ECW and the measured ECW [9]. The BCM has been validated with isotope dilution methods against all available goldstandard methods in the healthy population and in patients on dialysis [10-12].

\section{Physician's practical treatment guidelines according to the volume status}

The target BWT will be within 1 liter of the dry BWT. After randomization, participants in the control group will undergo BCM measurement at the beginning and end of the study. Both the physicians and participants will be blinded to the results. The physicians will prescribe PD solutions, drugs, and diet based on the clinical information that they obtain. Participants in the treatment group will undergo BCM measurement every 2 months over a 1-year period. Both the physicians and the participants will be notified of the results. Based on the $\mathrm{BCM}$ results combined with the clinical information, the physicians will prescribe PD solutions, diuretics, and diets. Figures 2 and 3 show the management of hypervolemia and hypovolemia, respectively.

Participants who switch to HD or combined dialysis (PD with intermittent $\mathrm{HD}$ ), receive kidney transplantation, transfer to other institutions, or die during the study will be dropped out of the study. Investigators or research coordinators will evaluate treatment adherence and give scores for each particular item, including 1) percentage of self-reported medical records $>80 \%, 2$ ) percentage receiving PD solutions $>80 \%, 3$ ) adherence to examinations including complete blood count (CBC), chemistry, peritoneal equilibrium test, $\mathrm{Kt} / \mathrm{V}$ (where $\mathrm{K}$ is dialyzer clearance of urea, $\mathrm{t}$ is dialysis time, and $\mathrm{V}$ is volume of distribution of urea, approximately equal to the patient's total body water), and 4) adherence to the scheduled visits.

\section{Clinical and laboratory evaluations}

Physical examination, medication reviews including PD solutions, fluid balance evaluation (semi-quantitative scale),. and laboratory evaluations, including $\mathrm{CBC}$, electrolytes, Cr, protein, albumin, calcium, phosphorous, and fasting glucose will be conducted every 2 months.

Laboratory evaluations, including total cholesterol, triglyceride, low-density lipoprotein cholesterol, hs-CRP, hemoglobin $\mathrm{A} 1 \mathrm{C}$, intact parathyroid hormone, Nterminal prohormone of brain natriuretic peptide, cardiac troponin $\mathrm{T}$, and weekly $\mathrm{Kt} / \mathrm{V}_{\text {urea }}$, will be performed at months 0 and 12 of treatment. Echocardiography will be performed, and PWV will be measured using a Colin pulse waveform analyzer (Colin CO, Ltd, Komaki, Japan) at months 0 and 12 after treatment. The study schedule is shown in Table 1. 


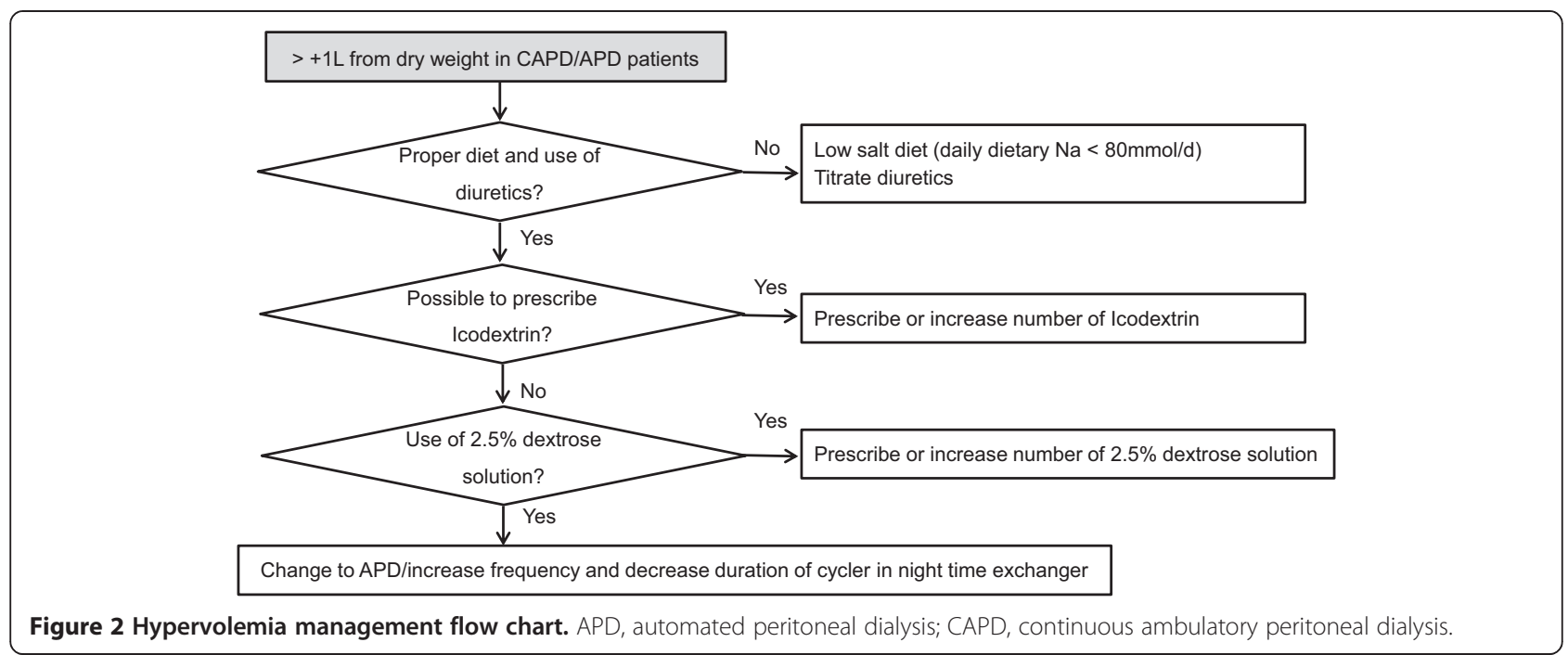

\section{Safety issues}

The BIS method approved by the US Food and Drug Administration has been used in clinical practice, particularly in Europe. Weak alternating currents into the body are known to be not harmful.

\section{Sample size calculations}

No previous report has evaluated the effect of BIS-guided fluid management on RRF in patients on PD. We therefore referred to a study showing that GFR changes over 1 year in a conventional PD solution treatment group and in a biocompatible PD solution treatment group were $-16.8 \pm 19.9$ and $0.09 \pm 40.9 \mathrm{l} /$ week $/ 1.73 \mathrm{~m}^{2}$, respectively [13]. We adjusted the sample size for an estimated dropout rate of $20 \%$ due to poor compliance, a two-sided level of significance of $\alpha=5 \%$, and a power of $80 \%$, and found that 69 participants will be required in each group to find a significant difference using Student's $t$-test. A total of 138 participants will be included in the analysis.

\section{Statistical analyses}

The statistical analyses will be conducted both on a perprotocol (PP) and an intention-to treat (ITT) basis. For PP analysis, all participants who complete the study will be included to evaluate the primary and secondary outcomes. For the ITT analysis, all participants who are enrolled and randomized to one of the two groups and who complete the first visit will be included.

Basic statistics will be reported in terms of mean \pm SD for continuous variables, or as percentages for categorical

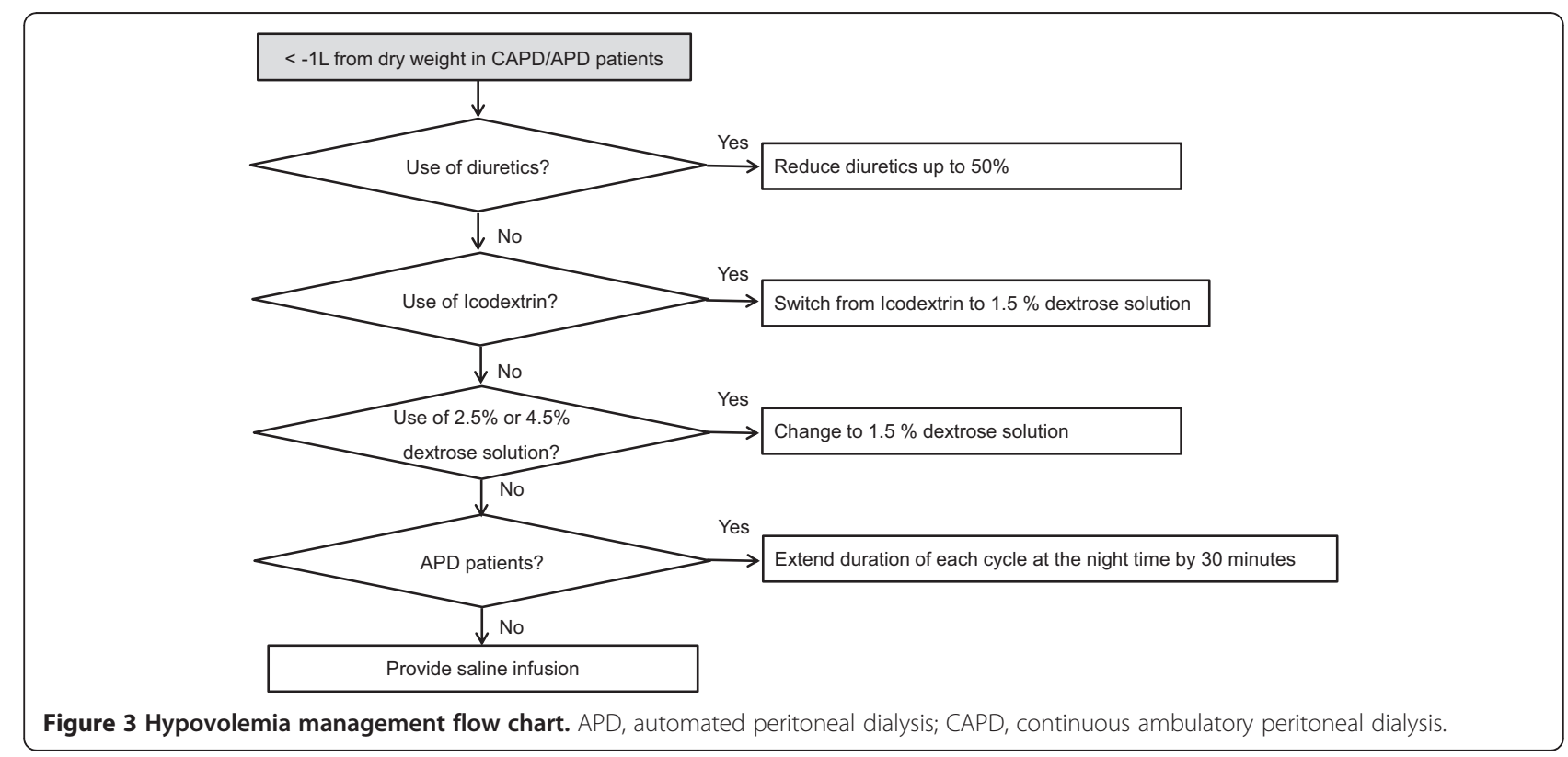


Table 1 Data collection schedule of the COMPASS study

\begin{tabular}{|c|c|c|c|c|c|c|c|c|}
\hline \multirow[t]{2}{*}{ Parameter } & \multicolumn{7}{|c|}{ Visit time (months) } & \multirow[b]{2}{*}{12} \\
\hline & -1 & 0 & 2 & 4 & 6 & 8 & 10 & \\
\hline Demographic information & $x$ & & & & & & & \\
\hline Charlson Comorbidity Index & $x$ & & & & & & & \\
\hline Physical examination ${ }^{1}$ & $x$ & $x$ & $x$ & $x$ & $x$ & $x$ & $x$ & $x$ \\
\hline Medication review ${ }^{2}$ & $x$ & $x$ & $x$ & $x$ & $x$ & $x$ & $x$ & $x$ \\
\hline Routine laboratory data ${ }^{3}$ & & $x$ & $x$ & $x$ & $x$ & $x$ & $x$ & $x$ \\
\hline Special laboratory data ${ }^{4}$ & & $x$ & & & & & & $x$ \\
\hline RRF, urine volume & & $x$ & & & & & & $X$ \\
\hline Compliance & & $x$ & $x$ & $x$ & $X$ & $x$ & $X$ & $X$ \\
\hline New events ${ }^{5}$ & & $x$ & $x$ & $x$ & $X$ & $x$ & $X$ & $X$ \\
\hline \multicolumn{9}{|l|}{ BCM measurement } \\
\hline Treatment group & & $x$ & $x$ & $x$ & $X$ & $x$ & $X$ & $X$ \\
\hline Control group & & $x$ & & & & & & $x$ \\
\hline $\mathrm{Kt} / \mathrm{V}$ & & $x$ & & & & & & $X$ \\
\hline Peritoneal equilibration test & & $x$ & & & & & & \\
\hline PWV & & $x$ & & & & & & $X$ \\
\hline Echocardiography & & $x$ & & & & & & $X$ \\
\hline PD solution, medication change & & $x$ & $x$ & $x$ & $x$ & $x$ & $x$ & $x$ \\
\hline
\end{tabular}

BCM, Body composition monitoring; COMPASS, Control Of fluid balance guided by body composition Monitoring in patients on PeritoneAl dialySiS trial; Kt/V, Calculated using single pool equation; PD, Peritoneal dialysis; PWV, Pulse wave velocity; RRF, Residual renal function.

${ }^{1}$ Includes body weight with an empty abdomen, blood pressure, pulse rate, and edema.

${ }^{2}$ Number of anti-hypertensive medications and diuretics and the type of PD solution.

${ }^{3}$ Complete blood count, electrolyte, serum creatinine, protein, albumin, calcium, phosphorous, and fasting glucose.

${ }^{4}$ Total cholesterol, triglyceride, low-density lipoprotein cholesterol, highsensitivity C-reactive protein, hemoglobin A1C, intact parathyroid hormone, $\mathrm{N}$-terminal prohormone of brain natriuretic peptide, and cardiac troponin $\mathrm{T}$.

${ }^{5}$ Any new clinical event, including hospitalization and peritonitis, will be recorded during the study period.

variables. Differences between groups will be analyzed using Student's $t$-test for continuous variables and the $\chi^{2}$ test or Fisher's exact test for categorical variables. The difference in GFR between month 0 and month 12 will be compared between the two groups using Student's $t$-test for the primary outcome. Analysis of covariance (ANCOVA) will be used to analyze the primary outcome as the secondary analysis to adjust the baseline value. Multivariate Cox proportional hazard regression models will be used to analyze the time to development of anuria. Although the institutions are mainly located in large cities, thereby limiting the likelihood of any important cluster effect, we will be sure to accommodate possible clustering in our models and analysis as required. A value of $P<0.05$ will be considered statistically significant. All analyses will be performed using SPSS Statistics software (v21.0; IBM Corporation, Armonk, NY, USA).

\section{Ethics approval}

The study will be performed in accordance with the Declaration of Helsinki, as amended by the 59th World Medical Association General Assembly in 2008. All the participants will provide signed, informed, written consent, stating that participation is voluntary and can be withdrawn at any time. Approval for the study has been obtained from the institutional review board of Seoul National University Bundang Hospital (E-1303/194001), Seoul National University Hospital (H-1302-050465), Seoul National University Boramae Medical Center (16-2013-30), Gachon University Gil Hospital (GAIRB2013-119), and Wonju Severance Christian Hospital (CR312065). The trial protocol has been registered at http://www.clinicaltrials.gov (NCT01887262).

\section{Discussion}

Preservation of RRF has been shown to be associated with a reduction in mortality, and has become one of the prime objectives in the treatment of patients on PD $[14,15]$. Controversy remains about whether hypervolemia or strict volume control helps preserve RRF in these patients $[3,16,17]$. Other groups have reported that BIS may be superior to clinical information in the assessment of fluid status for patients on HD or PD $[2,9,12,18]$. However, no studies have evaluated the effect of regular and serial BIS-guided fluid management on RRF in patients receiving PD. To our knowledge, this is the first multicenter, prospective, randomized controlled trial assessing whether BIS-guided volume management attenuates the loss of RRF. The endpoints of the COMPASS (Control Of fluid balance guided by body composition Monitoring in patients on PeritoneAl dialySiS) study are of the utmost importance to healthcare providers.

The strength of the study is that only subjects who are on PD for more than 1 month are eligible. This criterion reduces the likelihood of a pre-dialytic uremic factor confounding the primary outcome. Potential covariates, such as, the differences in treatment strategies between physicians, can also be minimized because physicians will prescribe PD solutions, diuretics, and diet according to the same protocol. Therefore, it is reasonable that the type and number of PD solutions and diuretics should serve as the secondary outcomes.

The $\mathrm{OH}$ value has been widely used in the assessment of volume status in patients on $\mathrm{PD}$ [19-21]. Additionally, O'Lone et al. recently reported the clinical significance of the $\mathrm{OH}$ index, - an accurate value of overhydration that was an independent predictor of mortality in contrast to the ECW/total body water (TBW) [22]. Different BIS parameters, such as ECW/TBW, ECW normalized for height, the $\mathrm{OH}$ value, and tissue hydration, have been used as indices of hydration in previous studies $[6,9,10]$. In other words, there is no definite BIS parameter for 
assessing the hydration status. In this respect, the usefulness and relevance of BIS various parameters will be determined in the present study.

Based on normal hydration being defined as ECW within \pm 1.1 liter of the 10th to the 90th percentiles in healthy subjects [10], previous studies for patients on HD have applied the same criteria [23-25]. Although some studies have suggested cutoff thresholds for the definition of the $\mathrm{OH}$ in patients on $\mathrm{HD}$ and patients on PD of 2.5 and 2.0 liters, respectively [19,26,27], we consider an ECW within \pm 1.1 liter as normal hydration.

There is a chance that patients within the same institution will be more correlated than patients between institutions. To avoid this, we will investigate for possible clustering of patients at the recruitment institution level, and will accommodate such clustering in our models and analysis as required. We also conservatively calculate the sample size, assuming a high drop-out rate, to overcome this potential problem.

A limitation of this study is that we will include both prevalent and incident patients on PD. Although a study targeting only incident patients on PD might provide more solid results, we will adjust the dialysis vintage in the multivariable analyses.

In summary, the COMPASS study is the first prospective, randomized controlled trial to evaluate the clinical usefulness of BIS-guided fluid management in patients on PD. The aim of this study is to evaluate whether BISguided fluid management has a beneficial effect on the decline of RRF, cardiac parameters, and cardiovascular outcomes.

\section{Trial status}

This trial is ongoing. Participants are currently being recruited.

\section{Abbreviations}

BP: Blood pressure; BIS: Bioimpedance spectroscopy; BWT: Body weight; CBC: Complete blood count; Cr: Creatinine; ECW: Extracellular water; GFR: Glomerular filtration rate; HD: Hemodialysis; hs-CRP: High-sensitivity C-reactive protein; ICW: Intracellular water; ITT: Intention-to treat; $\mathrm{OH}$ : Overhydration; PD: Peritoneal dialysis; PP: Per-protocol; PWV: Pulse wave velocity; RRF: Residual renal function; TBW: Total body water.

\section{Competing interests}

The authors declare that they have no competing interests.

\section{Authors' contributions}

$\mathrm{SHB}$ participated in the design of the study and drafted the manuscript. $\mathrm{KHO}$ conceived of the study, participated in the design of the statistical analysis, and helped draft the manuscript. SK, DKK, KWJ, YKO, BGH, JHC, WC, and YSK participated in the design of the study. KYN conceived of the study, participated in acquiring funding, and had final responsibility for the decision to submit for this manuscript for publication. All authors read and approved the final manuscript submission.

\section{Acknowledgements}

The trial is funded by Fresenius Medical Care Korea Ltd.

\section{Author details}

${ }^{1}$ Department of Internal Medicine, Seoul National University Bundang Hospital, 82, Gumi-ro 173 Beon-gil, Bundang-gu, Seongnam 463-707, Gyeonggi-do, South Korea. ${ }^{2}$ Seoul National University Hospital, Seoul, South Korea. ${ }^{3}$ Seoul National University Boramae Medical Center, Seoul, South Korea. ${ }^{4}$ Wonju Severance Christian Hospital, Wonju, South Korea. ${ }^{5}$ Gachon University Gil Hospital, Incheon, South Korea.

Received: 30 June 2014 Accepted: 22 October 2014

Published: 6 November 2014

\section{References}

1. Chen W, Guo LJ, Wang T: Extracellular water/intracellular water is a strong predictor of patient survival in incident peritoneal dialysis patients. Blood Purif 2007, 25:260-266.

2. Van Biesen W, Williams JD, Covic AC, Fan S, Claes K, LichodziejewskaNiemierko M, Verger C, Steiger J, Schoder V, Wabel P, Gauly A, Himmele R, EuroBCM Study Group: Fluid status in peritoneal dialysis patients: the European Body Composition Monitoring (EuroBCM) study cohort. PLoS One 2011, 6(2):e17148.

3. Jansen MA, Hart AA, Korevaar JC, Dekker FW, Boeschoten EW, Krediet RT: Predictors of the rate of decline of residual renal function in incident dialysis patients. Kidney Int 2002, 62(3):1046-1053.

4. Cocchi R, Degli Esposti E, Fabbri A, Lucatello A, Sturani A, Quarello F, Boero R, Bruno M, Dadone C, Favazza A, Scanziani R, Tommasi A, Giangrande A: Prevalence of hypertension in patients on peritoneal dialysis: results of an Italian multicentre study. Nephrol Dial Transplant 1999, 14(6):1536-1540.

5. Davies SJ, Brown EA, Reigel W, Clutterbuck E, Heimburger O, Diaz NV, Mellote GJ, Perez-Contreras J, Scanziani R, D'Auzac C, Kuypers D, Divino Filho JC, EAPOS Group: What is the link between poor ultrafiltration and increased mortality in anuric patients on automated peritoneal dialysis? Analysis of data from EAPOS. Perit Dial Int 2006, 26(4):458-465.

6. Hyun SH, Choi JY, Cho JH, Park SH, Kim CD, Kim YL: Assessment of fluid and nutritional status using multifrequency bioelectrical impedance analysis in peritoneal dialysis patients. Blood Purif 2014, 37(2):152-162.

7. Herget-Rosenthal S, von Ostrowski M, Kribben A: Definition and risk factors of rapidly declining residual renal function in peritoneal dialysis: an observational study. Kidney Blood Press Res 2012, 35(4):233-241.

8. Singhal MK, Bhaskaran S, Vidgen E, Bargman JM, Vas SI, Oreopoulos DG: Rate of decline of residual renal function in patients on continuous peritoneal dialysis and factors affecting it. Perit Dial Int 2000, 20(4):429-438

9. Hur E, Usta M, Toz H, Asci G, Wabel P, Kahvecioglu S, Kayikcioglu M, Demirci MS, Ozkahya M, Duman S, Ok E: Effect of fluid management guided by bioimpedance spectroscopy on cardiovascular parameters in hemodialysis patients: a randomized controlled trial. Am J Kidney Dis 2013, 61(6):957-965.

10. Wabel P, Chamney P, Moiss U, Jirka T: Importance of whole-body bioimpedance spectroscopy for the management of fluid balance. Blood Purif 2009, 27(1):75-80.

11. MoissI UM, Wabel P, Chamney PW, Bosaeus I, Levin NW, Bosy-Westphal A, Korth O, Muller MJ, Ellegard L, Malmros V, Kaitwatcharachai C, Kuhlmann MK, Zhu F, Fuller NJ: Body fluid volume determination via body composition spectroscopy in health and disease. Physiol Meas 2006, 27(9):921-933.

12. Crepaldi C, Soni S, Chionh CY, Wabel P, Cruz DN, Ronco C: Application of body composition monitoring to peritoneal dialysis patients. Contrib Nephrol 2009, 163:1-6.

13. Kim S, Oh J, Chung W, Ahn C, Kim SG, Oh KH: Benefits of biocompatible PD fluid for preservation of residual renal function in incident CAPD patients: a 1-year study. Nephrol Dial Transplant 2009, 24(9):2899-2908.

14. Maiorca R, Brunori G, Zubani R, Cancarini GC, Manili L, Camerini C, Movilli E, Pola A, d'Avolio G, Gelatti U: Predictive value of dialysis adequacy and nutritional indices for mortality and morbidity in CAPD and HD patients. A longitudinal study. Nephrol Dial Transplant 1995, 10(12):2295-2305.

15. Bargman JM, Thorpe KE, Churchill DN: Relative contribution of residual renal function and peritoneal clearance to adequacy of dialysis: a reanalysis of the CANUSA study. J Am Soc Nephrol 2001, 12(10):2158-2162.

16. McCafferty K, Fan S, Davenport A: Extracellular volume expansion, measured by multifrequency bioimpedance, does not help preserve 
residual renal function in peritoneal dialysis patients. Kidney Int 2014, 85(1):151-157.

17. Davenport A, Sayed RH, Fan S: Is extracellular volume expansion of peritoneal dialysis patients associated with greater urine output? Blood Purif 2011, 32(3):226-231.

18. Luo YJ, Lu XH, Woods F, Wang T: Volume control in peritoneal dialysis patients guided by bioimpedance spectroscopy assessment. Blood Purif 2011, 31(4):296-302.

19. Luo YJ, Wang T: What is the upper limitation of volume in Chinese peritoneal dialysis patients? Blood Purif 2011, 31(4):289-295.

20. Cader RA, Gafor HA, Mohd R, Kong NC, Ibrahim S, Wan Hassan WH, Abdul Rahman WK: Assessment of fluid status in CAPD patients using the body composition monitor. J Clin Nurs 2013, 22(5-6):741-748.

21. Hur E, Gungor O, Musayev O, Usta M, Toz H, Asci G, Ozkahya M, Duman S, Ok E: Bioimpedance spectroscopy for the detection of hypervolemia in peritoneal dialysis patients. Adv Perit Dial 2011, 27:65-70.

22. O'Lone EL, Visser A, Finney H, Fan SL: Clinical significance of multifrequency bioimpedance spectroscopy in peritoneal dialysis patients: independent predictor of patient survival. Nephrol Dial Transplant 2014 29(7):1430-1437.

23. Passauer J, Petrov H, Schleser A, Leicht J, Pucalka K: Evaluation of clinical dry weight assessment in haemodialysis patients using bioimpedance spectroscopy: a cross-sectional study. Nephrol Dial Transplant 2010, 25(2):545-551.

24. Gallar-Ruiz P, Digioia C, Lacalle C, Rodriguez-Villareal I, Laso-Laso N, Hinostroza-Yanahuaya J, Oliet-Pala A, Herrero-Berron JC, Ortega-Marcos O, Ortiz-Libreros M, Mon-Mon C, Cobo-Jaramillo G, Vigil-Medina A: Body composition in patients on haemodialysis: relationship between the type of haemodialysis and inflammatory and nutritional parameters. Nefrologia 2012, 32(4):467-476

25. Kim S, Sung J, Jung ES, Park HC, Lee H, Chin HJ, Kim DK, Kim YS, Han JS, Joo $\mathrm{KW}$ : Hemodynamic and biochemical benefits of the objective measurement of fluid status in hemodialysis patients. Tohoku J Exp Med 2012, 228(2):125-133.

26. Wabel P, Moiss U, Chamney P, Jirka T, Machek P, Ponce P, Taborsky P, Tetta C, Velasco N, Vlasak J, Zaluska W, Wizemann V: Towards improved cardiovascular management: the necessity of combining blood pressure and fluid overload. Nephrol Dial Transplant 2008, 23(9):2965-2971.

27. Wizemann V, Wabel P, Chamney P, Zaluska W, Moissl U, Rode C, Malecka-Masalska T, Marcelli D: The mortality risk of overhydration in haemodialysis patients. Nephrol Dial Transplant 2009, 24(5):1574-1579.

doi:10.1186/1745-6215-15-432

Cite this article as: Baek et al.: Control of fluid balance guided by body composition monitoring in patients on peritoneal dialysis (COMPASS): study protocol for a randomized controlled trial. Trials 2014 15:432.

\section{Submit your next manuscript to BioMed Central and take full advantage of:}

- Convenient online submission

- Thorough peer review

- No space constraints or color figure charges

- Immediate publication on acceptance

- Inclusion in PubMed, CAS, Scopus and Google Scholar

- Research which is freely available for redistribution 